no propulsion. These observations do not contradict the hypothesis that leaping can only occur if sufficient momentum is achieved at the anterior end, and to do this a water drop of the kind illustrated in Fig. 1 appears to be necessary.

C.S.I.R.O.

E. M. REED

Division of Entomology, Canberra, A.C.T.

C.S.I.R.O.

H. R. WALLACE

Horticultural Research Section,

Glen Osmond, Adelaide, South Australia.

${ }^{1}$ Dutky, S. R., and Hough, W. S., Proc. Ent. Soc. Wash., 57, 244 (1955). 2 Welch, H. E., and Briand, L. J., Canad. Ent., 93, 759 (1961).

\section{Vascular Supply of the Pituitary Gland in Channa punctatus Bloch}

THE median eminence and the true portal system of the higher vertebrates have not been observed in the teleost pituitary, although the blood vascular supply of the teleost pituitary has been described by Bretschneider and de Wit ${ }^{1}$, Green ${ }^{2}$ and Barrington ${ }^{3}$ in some detail. It is often reported that the pituitary gland in teleosts receives a direct blood supply from the internal carotid arteries and that the neurohypophysis and the adenohypophysis share a common vascularization. On this basis Green ${ }^{2}$ homologizes the neurohypophysis of the fish pituitary with the median eminence of the higher vertebrates. Barrington ${ }^{3}$ has attempted to show some degree of resemblance between the richly vascularized portion of the infundibulum of the minnow and the median eminence of Rana. However, he denies the existence of a true portal system in the minnow as most of the blood enters the gland directly through a 'ring vessel'.

The vascular supply of the pituitary gland in Channa punctatus shows some peculiar features. It has been studied in serial sections of $22-\mathrm{mm}$ fish. The pituitary

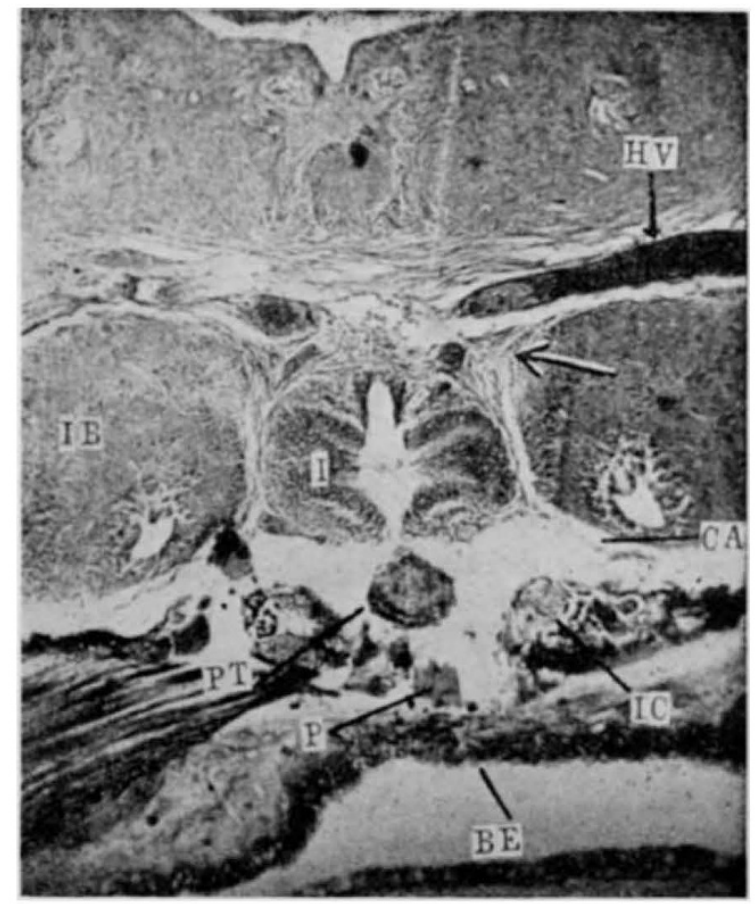

Fig. 1. Transverse section through the pituitary region of $22-\mathrm{mm}$ flsh $(\times 70)$. $B E$, buccal epithelium; $C A$, cerebral arteries; $H V$, head vein; sphenoid bone; $P T$, pituitary gland. Richly vascularized region is shown by arrow gland is fully formed at this stage ${ }^{4}$. The pars intermedia is richly vascularized and the blood capillaries are seen mostly in close relation to the finger-like nerve processes of the neurohypophysis. The pars distalis has a meagre blood supply. Reconstructions from serial sections indicate that the internal carotid arteries entering the hypophysial fenestra give rise to cerebral arteries which vascularize that region of the hypothalamus which is in close contact with the infundibulum (Fig. 1). This region is also in contact with head veins through the pituitary veins. There are indications that the richly vascularized hypothalamic region of the brain is in close contact with the pituitary gland through blood capillaries which are sometimes continuous and sometimes discontinuous. These blood capillaries travel by the sides of the infundibulum median to the inferior lobes and pass down into the pituitary gland.

From this account it appears that the pituitary has no direct blood supply but is dependent on the hypothalamus. The blood circulates through the capillary network of this region of the diencephalon and then passes down into the pituitary gland. This richly vascularized region of the diencephalon thus appears to be functionally comparable with the median eminence of higher vertebrates, as evidenced by the distribution of the neurosecretory fibres in this region. It seems, therefore, that the pattern of the blood vascular system in $C$. punctatus bears some resemblance to that found in higher forms.

I thank Mrs. A. Belsare for her help in reconstructing the course of the blood vessels from serial sections, and Prof. H. Swarup for his advice.

Post-Graduate Department of Zoology,

Nagpur University, Nagpur, India.

${ }^{2}$ Bretschneider, L. H., and de Wit, J. J. D., Sexual Endocrinology of NonMammalian Vertebrates (Amsterdam, 1947)

${ }^{2}$ Green, J. D., Amer. J. Anat., 88, 225 (1951).

Barrington, E. J. W., Proc. Zool. Soc. Lond., 135, 551 (1960).

- Belsare, D. K., J. Morph., 131, 151 (1963).

\section{Precise Localization of Renshaw Cells with a New Marking Technique}

For some years Renshaw cells in the spinal cord have been extensively investigated. While their physiological and pharmacological properties are relatively well known, knowledge concerning their location in the spinal cord is only approximate and is mostly derived from electrophysiological observations ${ }^{\mathfrak{1}}$ and indirect anatomical evidence $^{2}$. From all this work it has been concluded that Renshaw cells are located in the ventral horn medial to motoneurones. For accurate localization of these and other cells within the central nervous system, however, it is necessary to record the electrical activity with microelectrodes which have satisfactory electrical properties, and then to indicate the location of the electrode tip by making, while causing a minimum of damage to the area, a small and easily identifiable mark. A number of techniques have been used for locating the position of microelectrode tips in nervous tissue ${ }^{3}$. However, most of these techniques require special histological procedures, may be unreliable, or can only be used at the end of an experiment. While the method of Galifret and Szabo ${ }^{4}$ needs no special histological procedure and can be used several times in an experiment, it makes rather large marks (several hundred $\mu$ ) and has not proved completely reliable. We have therefore developed a new technique for routinely making precise, easily located marks and have used this technique in localizing Renshaw cells.

Acute decapitate cats were prepared in the usual manner, and, after lumbosacral laminectomy, Renshaw cells were located and the characteristic discharge of single units identified as previously described ${ }^{\mathbf{1}, 5}$. The electrodes used for recording and marking were prepared by filling 